\title{
INTRAOPERATIVE REAL-TIME VISUALIZATION OF CORONARY ARTERIES BY MEANS OF POWER DOPPLER ECHOCARDIOGRAPHY: PRELIMINARY EXPERIENCE
}

Tetsuo Sakakibara, MD, ${ }^{a}$ Ryousuke Matsuwaka, $\mathrm{MD},{ }^{\mathrm{a}}$ Fuminobu Ishikura, MD, ${ }^{\mathrm{b}}$ Masataka Mitsuno, MD, ${ }^{\mathrm{a}}$ Akihiko Yagura, MD, ${ }^{\mathrm{a}}$ and Kazuhisa Kodama, MD, ${ }^{\mathrm{b}}$ Osaka, Japan

Various attempts have been made to achieve intraoperative visualization of the coronary arteries, ${ }^{1-4}$ but no technique is widely accepted. Power Doppler echocardiography is reported to be better for imaging slow-flow vessels than is the conventional color Doppler method. ${ }^{5}$ We applied this technique for intraoperative real-time assessment of coronary perfusion and anatomy.

Intraoperative echocardiography was performed in 10 adults undergoing cardiac operations with the aid of cardiopulmonary bypass (coronary artery bypass grafting in five and valve replacement in five). During the infusion

From the Divisions of Cardiovascular Surgery ${ }^{\mathrm{a}}$ and Cardiology, Cardiovascular Center, Osaka Police Hospital, Osaka, Japan.

Received for publication July 25, 1996; accepted for publication August 13, 1996.

Address for reprints: Tetsuo Sakakibara, MD, Cardiovascular Surgery, Osaka Police Hospital, 10-31, Kitayamacho, Tennouji-ku, Osaka 543, Japan.

J Thorac Cardiovasc Surg 1997;113:605-6

Copyright (C) 1997 by Mosby-Year Book, Inc.

$0022-5223 / 97 \$ 5.00+0 \quad \mathbf{1 2 / 5 4 / 7 7 3 2 3}$ of cold blood cardioplegic solution or initial reperfusion with warm blood, a hand-held echo transducer $(6.5 \mathrm{MHz}$ wide band probe) was placed on the epicardium to obtain coronary artery images with power Doppler echocardiography using a LOGIQ 500 system (GE Yokogawa Medical, Tokyo, Japan). The transducer was covered with a sterile rubber bag to prevent the leakage of indirect current. Images were displayed as either black and white or color in real time. Fig. 1 shows an image of the left anterior descending coronary artery and its branches in a patient with normal coronary arteries. In all patients, this imaging method was useful for the evaluation of coronary perfusion during the delivery of cardioplegic solution.

Poor filling of the left anterior descending coronary artery was detected during infusion of cardioplegic solution via the aortic root in a patient with left main trunk disease. Subsequent retrograde infusion of cardioplegic solution achieved good filling of the artery, indicating adequate perfusion of the myocardium. Poor visualization of a coronary artery does not indicate inadequate myocardial perfusion during retrograde infusion, however.

This imaging method was also applied to evaluate graft

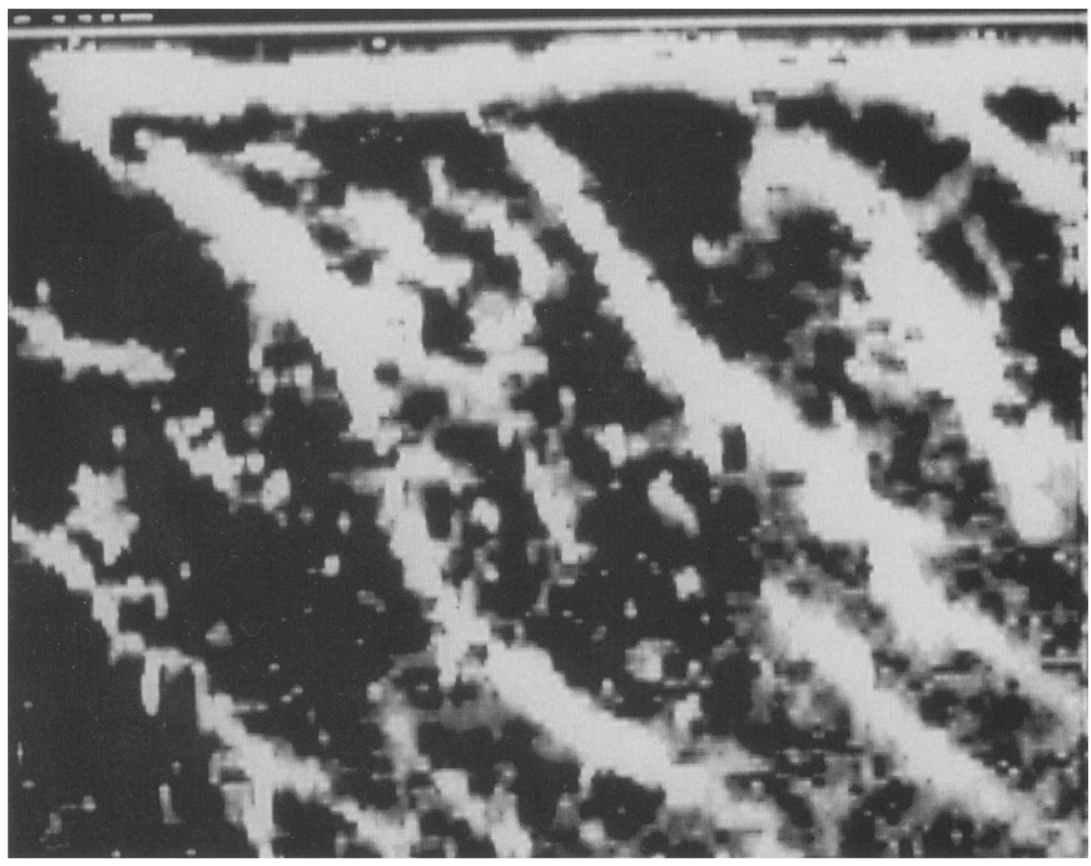

Fig. 1. Power Doppler coronary angiogram of the left anterior descending artery and its branches in a patient who has normal coronary arteries. 


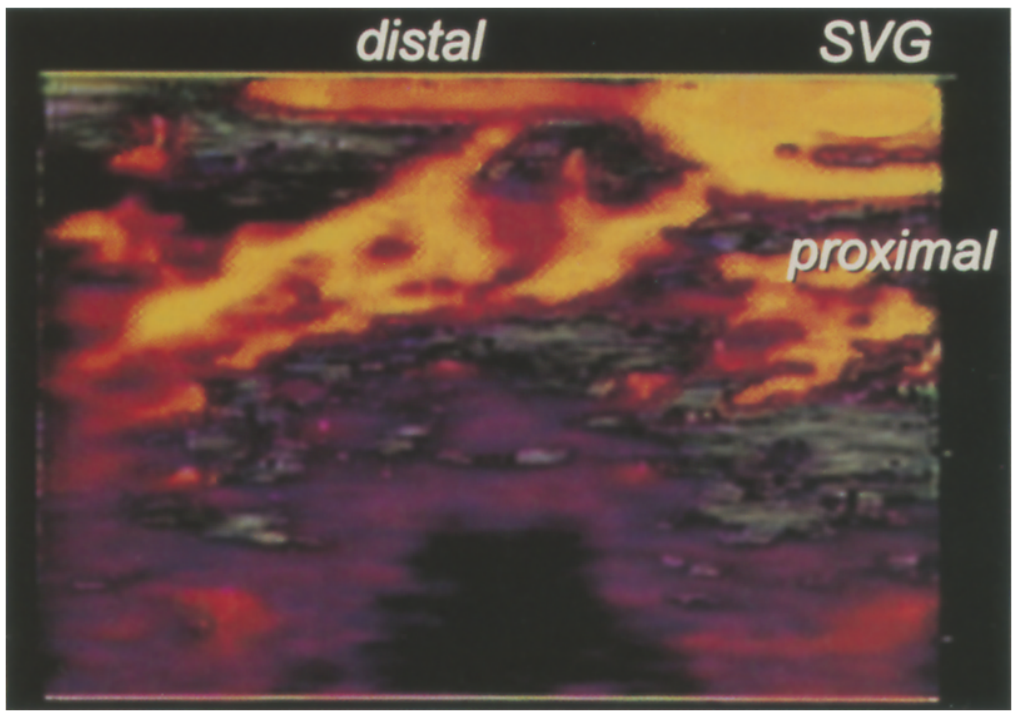

Fig. 2. Power Doppler coronary angiogram of a patient with coronary artery bypass grafting demonstrates optimal anastomosis of a saphenous vein graft $(S V G)$ to the first diagonal branch.

patency, anastomotic anatomy, and native coronary artery stenosis in patients undergoing coronary artery bypass grafting. The graft was judged to be patent when the artery distal to the anastomosis was clearly imaged or the anastomotic site was directly visualized during injection of cardioplegic solution into the vein graft or during warm blood reperfusion of the internal thoracic artery graft. Fig. 2 shows an image of a vein graft anastomosis.

This preliminary study suggested that power Doppler echocardiography has several advantages over previous methods for intraoperative visualization of the coronary arteries. Power Doppler echocardiography can provide both long-axis and short-axis images. Long-axis images can be used to assess perfusion, whereas short-axis images may be useful for evaluation of target vessel size. This technique is not a totally new method, but is merely a more sophisticated version of Doppler ultrasonography. Inasmuch as intraoperative echocardiography (generally transesophageal echocardiography) is widely available, no additional preparations except for provision of a small hand-held transducer are necessary to perform power Doppler echocardiography. This technique also does not interfere with or delay the operation.

A major disadvantage, however, is the lack of information about the velocity or direction of flow. The linear probe used in our study was originally designed for imaging the liver or kidney, and there was some difficulty in observing the epicardial coronary arteries. A specially designed probe should be able to solve this problem. Despite such limitations, the power Doppler technique has the potential to be better than previous methods for intraoperative real-time imaging of coronary arteries in the arrested heart. Further clinical experience and improvement of the technology may establish this method as a valuable intraoperative imaging modality.

\section{REFERENCES}

1. Chaux A, Lee ME, Blanche C, Kess RM, Sherman TC, Hickey $\mathrm{AE}$, et al. Intraoperative coronary angioscopy: technique and results in the initial 58 patients. J Thorac Cardiovasc Surg 1986;92:972-6.

2. Mohr FW, Matloff J, Grundfest W, Chaux A, Kass R, Blanche $C$, et al. Thermal coronary angiography: a method for assesing graft patency and coronary anatomy in coronary bypass surgery. Ann Thorac Surg 1989;47:441-9.

3. Sahn DJ, Barratt-Boyes BG, Graham K, Kerr A, Roche A, Hill $\mathrm{D}$, et al. Ultrasonic imaging bf the coronary arteries in open-chest humans: evaluation of coronary atherosclerotic lesions during cardiac surgery. Circulation 1982;66:1034-44.

4. McPherson DD, Armstrong M, Rose E, Kieso RA, Megan M, Hunt $M$, et at. High frequency epicardial echocardiography for coronary artery evaluation: in vitro and vivo validation of arterial lumen and wall thickness measurements. J Am Coll Cardiol 1986;86:600-6.

5. Rubin JM, Bude RO, Carson PL, Bree RL, Adler RS. Power Doppler US: a potentially useful alternative to mean frequency-based color Doppler US. Radiology 1994;190:853-6. 